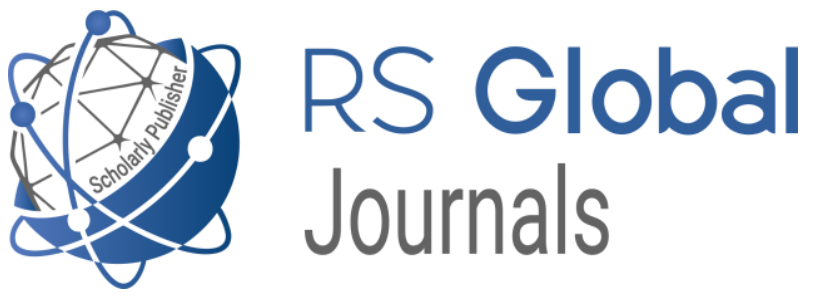

Scholarly Publisher

RS Global Sp. z O.O.

ISNI: 0000000484952390

Dolna 17, Warsaw, Poland 00-773

Tel: +48226022703

Email: editorial_office@rsglobal.pl

JOURNAL International Journal of Innovative Technologies in Social Science

p-ISSN

2544-9338

e-ISSN

2544-9435

PUBLISHER

RS Global Sp. z O.O., Poland

ARTICLE TITLE

AUTHOR(S)

ARTICLE INFO

DOI

RECEIVED

ACCEPTED

PUBLISHED

LICENSE
TEXT AS A PRAGMATIC ASPECT

Bashirova Gulnar Rasim

Bashirova Gulnar Rasim. (2021) Text as a Pragmatic Aspect. International Journal of Innovative Technologies in Social Science. 4(32). doi: 10.31435/rsglobal_ijitss/30122021/7738 https://doi.org/10.31435/rsglobal_ijitss/30122021/7738

05 November 2021

21 December 2021

25 December 2021

(c) (†)

This work is licensed under a Creative Commons Attribution 4.0 International License.

(C) The author(s) 2021. This publication is an open access article. 


\title{
TEXT AS A PRAGMATIC ASPECT
}

\author{
Bashirova Gulnar Rasim, PhD, associate professor, Azerbaijan Marine Academy, Chair of English, \\ Azerbaijan
}

DOI: https://doi.org/10.31435/rsglobal_ijitss/30122021/7738

\section{ARTICLE INFO}

Received 05 November 2021

Accepted 21 December 2021

Published 25 December 2021

\section{KEYWORDS}

descriptive approach, text structure, pragmatic settings, functional styles, cohesion.

\begin{abstract}
The structural analysis, as one of the types of descriptive approach, has traditionally been used to study the linguistic units in hierarchy. This analysis has made great contribution to all levels, including the level of syntax because syntax is by nature hierarchic. In sentence we cannot say or write two things at the same time. The sentences have to be presented one after the other, in linear order. Therefore the problem is how to signal hierarchies through linear presentation. One of such attempts has been made by the representatives of Prague School of Linguistics (Mathesius, 1967). The 'Praguean` influence has been widespread and long-lasting. Its main emphasis lay on the analysis of language as a system of functionally related units. The notion 'unit reminds in some way the Saussurean influence. In particular, it led to the distinction between the phonetic and the phonological analysis of sounds, the analysis of the phoneme into distinctive features as well as of the theme-rheme or communicative structure of sentence.
\end{abstract}

Citation: Bashirova Gulnar Rasim. (2021) Text as a Pragmatic Aspect. International Journal of Innovative Technologies in Social Science.4(32). doi: 10.31435/rsglobal_ijitss/30122021/7738

Copyright: (C) 2021 Bashirova Gulnar Rasim. This is an open-access article distributed under the terms of the Creative Commons Attribution License (CC BY). The use, distribution or reproduction in other forums is permitted, provided the original author(s) or licensor are credited and that the original publication in this journal is cited, in accordance with accepted academic practice. No use, distribution or reproduction is permitted which does not comply with these terms.

Introduction. In fact more common approach to defining text is communicative or functional. W. Dressler and R. de Beaugrande identifies "the seven standards of textuality: cohesion; coherence; intentionality; acceptability; informativity; situationality; intertextuality" (Dressler and de Beaugrande, 1980:20). Later R. de Beaugrande emphasizes the role of a text in the process of communication (de Beaugrande, 1981:9): Language occurrences may have the surface format of single words or sentences, but they occur as texts: meaningful configurations of language intended to communicate. G. Kolshanski also considers text from this angle (Kolshanski, 1981:89)

At present, we have to acknowledge that a text is functioning as the fragment of speech fulfilling cognitive, informative, psychological and social dimensions of interaction with certain structural criterion. As we have already mentioned, the 70 s and 80 s of the last century were very productive in terms of intensive explorations in the linguistic study of text but limited by analyzing only the connections between relatively a few sentences or semantically linked other fragments within text. Cohesion, which is regarded as a mean of structural unity of text is manifested thanks to a number of factors. In fact, each level of the structure of language makes contribution to the cohesion in text. And it is necessary to identify two common sets of connections. One of them is the connection of linear sequence between the components of text and the second one is the connection of multiple referential crossing between the components of text, i.e. the existence of implicit or explicit repetitions within the structure of text. We have to note that those connections in text seem to be manifested very closely and 'mutually knitted and ultimately intended to demand each other. On the other hand, their uses are related with the different levels of text.

It should also be taken into consideration that M.A.K. Halliday identifies the textual component of the grammar of English as consisting of the features associated with two groups of resources: the structural and the cohesive. The first is subdivided into the two areas - information structure and theme-rheme structure. The second is subdivided into four areas - reference, ellipsis and substitution, conjunction and lexical cohesion (Halliday and Hasan, 1976). 
Research methods. A characteristic of cohesive reference is that, on second and subsequent mention, instead of being named, the person or thing referred to may be indicated by means of a pronoun, demonstrative (this, these, etc.) or a comparative. The repetition of nominal may also have a cohesive function, but there is a special characteristic that is produced by the use of unnamed reference. When receivers come across a pronoun or a determiner, they have to mentally identify the linked nominal in order to make sense of the text. This has a very strong cohesive force. The term reference, as used by M.A.K. Halliday and R. Hasan, is an extension of the term as used in philosophy and some types of semantics to mean an act of referring to entities outside the discourse. Reference in this sense is not necessarily textually cohesive. These ideas have been developed recently within Systemic Functional Grammar identifying three main types of cohesive reference: personal reference, demonstrative reference and comparative reference (Halliday, Matthiesen, 2004). Personal reference depends on the use of personal pronouns (masculine, feminine and neuter). Possessives are also personal references, which are commonly referential. Demonstrative reference is dependent on the use of determiners (this, these, that and those) and adverbs (here, now, then, there). In case of comparative reference we use adjectives (same, other, identical, better, more) or their adverbial correspondences (identically, similarly, less, etc.) to forge links with previously mentioned entities.

Meanwhile, cohesion itself is not sufficient for comprehension of a text by the sender because although the organization of text via numerous and closely interrelated links between its components is quite simple, its inference and interpretation cause challenges. The connexity within a text is not only based on the links between words and sentences. There is a factor which allows to the receiver to put distinction between the meaningless but formally connected stretch of language and a meaningful text. This factor is coherence which N. Enkvist defines something existing not in language but in society. The problem is that in order to understand a text better it is necessary to explore the references beyond text. As a result a new approach gained momentum according to which alongside cohesion coherence is also mandatory for the study of text (Enkvist, 1989, etc.). N. Enkvist explains connexity using the following formula (Enkvist, 1989:375):

Connexity $=$ cohesion+coherence.

Further development in text linguistics focused on understanding that human interaction is based on communication through a text and even one phrase or sentence can function as a text. So, the study of text has become mainstream trend in modern linguistics considering its importance to model a communicative process. And, the rules of text organization depend on the communicative nature of a text rather than certain strict rules, i.e. a text is not the static but the communicative unit with changing boundaries subject to the relevant communicative intention.

Scientific novelty of the research. The sense of a text is defined by how communicators understand and interpret it. Thus the focus is on the issues related to what information is marked in text considering the communicator's linguistic and cognitive knowledge as well as the situation where communication takes place. N. Enkvist writes (Enkvist, 1989: 376):

Whatever chunk of verbal expression satisfies certain functional criteria, for instance by occurring as a string which a suitably selected receiver intuitively feels to constitute a communicative unit of some specific and definable type in an authentic communicative situation, qualifies as a text.

Such definition places the burden on a receiver's intuitions to put distinction between text and nontext. We would like to refer to R. Wodak, who recalls the remarks made by L. Wittgenstein (Wodak, 2009:39): “...meanings are formed in use”. Excluding rare cases of deliberate meaningless in certain text types meaning becomes critical for the main function of text, i.e. to communicate. As background to the difficulties of defining the meaning of text there is an intuitive knowledge which the linguists share with the speech community. Any receiver is able to answer the question whether a piece of speech is text or not. N. Enkvist writes (Enkvist, 1989:375): “...text is whatever people feel." It happens on the basis of intuition, which also enables communicators to decide on the grammatical acceptability of sentence.

According to N. Enkvist, there are four different approaches to defining text from the most general to the most specific (Enkvist, 1989:370): "1) A text is a sequence of meaningful symbols.

2) A text is a meaningful sequence of symbols.

3) A text is a sequence of meaningful symbols in a natural language.

4) A text is a meaningful sequence of symbols in a natural language".

The fourth definition is the most central to our discussion and therefore the one worth discussing at length. We will focus our attention on the word meaningful. It seems obvious to require meaning of a text: a text must mean in order to function and its form must enable a receiver to derive 
meaning from it. But to have meaning a text must work in a certain authentic situation. A familiarity with the situational context, either in its original form in connection with the speech act or in a sufficiently complete and accurate reconstruction, may be needed before we understand what a text is all about. N. Enkvist also focused on the link between a text and the surrounding world (Enkvist, 1989: 371): ...to have meaning, a text must work in a certain authentic situation.

Developing the definition of text given by M.A.K. Halliday and R. Hasan (Halliday and Hasan, 1976) Th. Bloor and M. Bloor pay special attention to those who actually use texts (real people) and actual circumstances (Th. Bloor and M. Bloor, 2004: 5): A text is any stretch of language, regardless of length, that is spoken or written for the purposes of communication by real people in actual circumstances.

Theoretical significance of the research. When we consider the linguistic units from the communicative angle, some high evaluation criteria are used as the pragmatic factor dominates over other factors. It is due to the simple fact that language as a whole and all its elements fulfill an important social task to ensure communication among the members of social groups by exchange of actual information via the conventional signs. The communicative analysis of the linguistic units gives priority to only one criterion, i.e. the communicative efficiency. It is also the case for a text despite the fact that a text has never been considered (except few early researches) as the linguistic unit. Any manifestation of the linguistic code can be and must be approached from the angle of the communicative efficiency. Thus, the study of text mainly based on three major factors: structural (formal), semantic (meaning) and communicative (functional). In fact, the focus on these issues has gradually shifted the sphere of the linguistic interests from text to discourse.

Practical significance of the research. It should also be taken into consideration that linguistics has a long and contradictory tradition of the interpretation of text and discourse. For certain period of time the term "discourse" was used in the English speaking linguistics (Halliday and Hasan, 1976, Warner, 1980, etc.), whereas the term "text" was preferred in the German and Russian speaking linguistic traditions (Dressler, 1968, Galperin, 1980, etc.). This period was characterized by the intense use of both terms in order to identify the unit of grammar beyond sentence. The provisions of its identification as discourse and text were also given in the relevant researches among which two are most important: text or discourse should be formally and semantically connected whole. The semantic connectedness is necessary for the use of text in the process of human interaction, i.e. to realize certain pragmatic intention in text. On the other hand, text can exist in isolation from the outside world. The ancient written monuments are good example for that. But, of course, it is the rare case. Text should contain pragmatic effect and be socially motivated. Such an approach has become leading since the 80 's of the last century and introduced a new stage in the relationship between text and discourse. In this regard the classical definition of discourse given by N. Enkvist is quite symptomatic (Enkvist, 1989:372): ...discourse means text + context, where context contain a situational component. Thus, we can come to such simplistic conclusion that there is no discourse without text and context. In this regard, we are interested in the approaches to text and discourse within the linguistic, sociolinguistic and psycholinguistic researches. These issues have been under focus for the recent two decades.

The above - mentioned issue of the terminological differences between text and discourse caused the emergence of another quite serious problem which requires an explicit answer to the following question: what is the difference between text linguistics and discourse analysis? Originally, it is believed that discourse analysis aimed at the explorations of two major issues: 1) how text acquires meaning; 2) what makes text connected and interpretable? Discourse analysis mainly focuses on intertextuality. At the same time, text linguists also indicate its relevance for the studies of text. Text is viewed mostly as the formal construction used for messaging, while discourse is regarded on the level of mental processes and mainly explained by the extra-linguistic factors. Hence, discourse is the diversified actualization of a formal construction, i.e. a connected speech. But if we compare it with the similar definitions of text, such understanding of discourse does not shed a light on how to differ it from a text. N. Enkvist explains the difference between text and discourse as follows (Enkvist, 1989, 371-372): Those who are fond of this distinction usually define it in terms of whether we look at a text as divorced from its situational context, or as discourse and part of a situation, to cite a classis example, as long as No Smoking sign is on the desk of a linguist, who studies its linguistic structure as such and apart from its original situational context, it remains a text. But once it is hung on the wall, or is studied as a specimen of a text recovered from a wall in a specific kind of room and with a specific situation-bound function, it becomes a piece of discourse.

Therefore discourse analysis as a field of intertextual study represents a special interest to the sociologists, psychologists and other researchers in human and social sciences. Despite the obvious 
difficulties to put a clear difference between text and discourse (it sometimes causes the synthesis of text linguistics and grammar of text with discourse analysis), the above factor helps to understand the difference. Text is a final product or final result, whereas discourse is a process of text building. As we see a text can be studied as the real product of certain activity, while discourse is more complex. If we want to study it we have to reveal the idea and the intention of the sender, that is to say it is necessary to define presuppositions hidden behind the explicit linguistic form. Therefore, discourse analysis is mostly dealing with the extra-linguistic factors. A Kibrik writes (Kibrik, 1997: 30): Discourse is the notion larger than text. Discourse is both the process of language activity and its result, but the result is also a text.

We would like to reiterate the above-mentioned definition of discourse given by N. Enkvist (Enkvist, 1989) that it is the synthesis of text with context existing in social life. T. van Dijk gives a new approach to context (Dijk, 1998:23): As to the context, on the other hand, this is said to include the participants and their roles, goals settings and shared knowledge.

Developing this idea R. Wodak indicates four layers of context in Discourse-Historical Approach within Critical Discourse Analysis (Wodak, 2009: 38):

- the intertextual and interdiscoursive relationships between utterances, texts, genres and discourses;

- the extra-linguistic social /socio-logical variables;

- the history and archaeology of texts and organizations; and the institutional frames of the specific context of a situation.

And she concludes (Wodak, 2009:39): In this way, we are able to explore how discourses, genres and texts change due to socio-political contexts.

As we see from the above-mentioned remarks, text, context and discourse are closely interrelated with genres, which define pragmatic and cognitive perspectives in discourse.

Analyses. Discourse can be verbalized in the various genres such as literary, political, media, academic, etc. According to N. Fairclough genre or type may be characterized as "socially ratified way of using language in connection with a particular type of social activity" (Fairclough, 1995:27). There are two important factors, which are relevant for all discourse types. First, they all seem constructed to arouse and hold the interest of the receiver; and second, almost all types are strongly ideologically marked (Dijk, 1998). In this regard we would like to remind four basic characteristics for any type of discourse:

-it is fixed in text;

-it has a cognitive foundation;

-it is ideologically marked;

-it is culturally motivated.

But there are of course some differences as well. According to topic texts are divided into three broad categories: a) literary; b) institutional (media, political, etc.); c) academic or scientific. In contrary to the most media or political discourses literary and academic discourses (books, research papers) do not take place in real time, i.e. the prerequisites differ. Second, despite the obvious pragmatic intentions, as the major characteristics for all types of discourse, say, political or legal discourse tends to be more convincing, influencing and even manipulating rather than literary or academic discourse.

As communication takes place not only in the real life but also in the fictional world it is necessary to mark distinction between the texts of these two types of contexts. According to this criterion although some genres of the newspaper are fictional, many of them reflect real life events. The fundamental differences between the texts in real and in fictional discourse are conditioned by their contextual features. The fictional text does not address the receiver directly but only through the sender. The newspaper text aims to inform, to manipulate and to convince the receiver explicitly or implicitly. We can continue such juxtaposition of different texts. But ultimate goal is the realization of intention of both communicators resulted in the success of communication. This trend in text linguistics has brought to more distinctive approaches to the texts of different types.

The characteristic features of the real-life communication are the cooperative principles of the maxims of quality, quantity, relevance and manner (Grice, 1976). Meanwhile these maxims are not prerogatives for the literary discourse and they are frequently violated to create emotionality, ambiguity, vagueness and polysemy for various pragmatic and stylistic effects.

The main issues requiring special attention in the fictional or literary discourse are the internal world of the sender (writer or poet), his ther psychological mood while creating certain literary work, the sender's desire to be expressive or not (for instance, the difference between S. Maugham and E. Hemingway is quite relevant for this argument). In the literary text, linguistic structures, statements, arguments, promises, orders, apologies, influencing the receiver, encouraging or even urging to act do 
not address him her directly. All these messages are filtered via the consciousness of the sender, via the textual images as well as the receiver`s receptive powers. I. Galperin (Galperin, 1981) is quite right indicating that aesthetic, cognitive and actual information functions successfully integrated in literary text. He believes that the aesthetic-cognitive function of literature exceeds the function of factual information which is characteristic of real-life discourse. But it is also case for other types of discourse, for example written genres of political or media texts. On the other hand, literary, academic (research articles, monographs, lectures addressed on big audience) and newspaper discourses (analytical articles, comments) tend to be chaotic and virtual. Probably, it might be accounted for the senders` desire to invite the potential receiver to think. In contrary, political, legal and some academic discourses (regular lectures) lack such chaoticness and virtuality.

Discussion. Thus, the real world discourse is basically dialogic, whereas the literary discourse-polylogic.

If we look at the literary and media discourses, there are also obvious differences in the function of the literary texts which deliver story-telling or narrative and in the function of the media texts which deliver message. M. Talbot indicates at the genre hybridization in media discourse (Talbot, 2007). Traditionally it covers press, radio, television, etc. (Bertrand, 1995, etc.) and nowadays we can add also social networks.

The core of the informative function of language exists in media texts (Wodak, Busch, 2004), i.e. the facts of topic, extra-linguistic reality, including reported ideas or theories. Meanwhile few media texts are purely informative: most include expressive and vocative functions with an emphasis on one of the three. Many of these texts encourage an imaginary audience to spell out a variety of weak implicative along these lines persuading the audience. Nowadays vocative texts are more often addressed to a readership than a reader. The first factor in all vocative texts is the relationship between the writer and the readership, which is realized in various types of socially or individually determined grammatical relations or forms of address.

The second factor is that these texts must be written in a language that is immediately comprehensible to the receiver. However, strictly, vocative or informative texts do not contain the expressive function-it exists in these texts only unconsciously or implicitly. Most informative texts will either have a vocative thread running through them or vocative function concerns only certain parts of these texts related to recommendation, opinion or value-judgment. Any text can hardly be entirely informative, i.e. its certain part must imply subjectivity. Expressive texts usually carry message, the degree of its vocative component varies and is a matter of argument depending partly, at least, on its proportion of universal and cultural components. So, the epithets-expressive, informative and vocative are used only to show the emphasis of text.

Given the above-mentioned factors newspaper discourse represents a special interest among the types of discourse, which is considered as one of the richest functional styles.

The term newspaper implies that the related text is expected to reflect the events happened in the recent past as well as to comment and to analyze those events. Newspapers, therefore, contain news about certain events, but presentations of this news may vary. Despite the fact that with the development of online newspapers this rule is changing, the newspaper texts of both types have the similar characteristics: some news is presented in the form of information and some is presented in the form of a story-telling or narrative.

As the British newspapers are in the centre of our research there is an important division among those newspapers to be highlighted in this work. Traditionally they are divided into the broadsheet newspapers: the Guardian, the Times, etc., the middle-range tabloids: the Daily Mail, etc. and the tabloids: the Sun, The Mirror, etc. (Tunstall, 1996). The main differences between two kinds concern the structure of their texts as well as the proportion of news stories and advertising in these kinds: broadsheets contain more news reporting, whereas tabloids contain more advertising. But the recent trends show that all kinds of the newspapers tend to include more advertising due to the obvious market reasons. Newspapers in Britain operate within a free market system. If they are not successful commercially they will fail. Competition is seen to operate to ensure a high-quality product. If the newspaper is of a poor quality, then people will not buy it. Therefore, newspapers do not only contain news, they also contain comment, advertising, entertainment. Advertising is a vital source of revenue for all newspapers. Newspapers that attract a lot of advertising can sell their product at a lower price and afford a whole range of devices to make their product attractive to the potential audience.

In fact these differences condition the relevant genres in newspaper: news, comment and analysis, advertising, entertainment. In addition news, analytical articles, comments, entertainments 
pragmatically and stylistically vary. For example, news is traditionally neutral and contains main message to be delivered to the audience without considerable emphasizing. In the contrary the authors of the analytical articles have more freedom in terms of the distribution of information, which enables them to be flexible in the use of various linguistic devices for emphasizing. On the other hand, the reader of newspapers is not entirely the receiver of new information on recent events. He or she is the receiver of selected information on recent events, and this information may usually be presented with clear ideological marking that makes it very difficult for the reader to make judgment independently on what hislher actual view-point of these events is. Another important issue in presenting of news is that newspapers present facts in a way that is designed to arouse the reader`s interest and curiosity. It is also possible to present facts in a way that will influence the reader's view of them.

Thus, the newspaper text has strong pragmatic potential with the goal of creating a specific environment over the event it covers. We have also to take into account that stories about individuals whether they are celebrities or not- dominate the news, rather than stories about events. In this regard it is interesting to look how a sender of the news text use and even manipulate with that particular feature of this genre involving specific pragmatic strategy and relevant linguistic devices.

The basic characteristics for media discourse is the fact that argumentation prevails in this type. Any argumentation relies on the cause - effect or cause - result connections manifested through various linguistic devices or simply implied in discourse. A number of researchers (Halliday, Hasan, 1976, Abdullayev, 1983, Warner, 1984, Enkvist, 1989, etc) investigated the grammatical and lexical devices which signal cause effect connections used, first of all, to serve for certain pragmatic goals of the sender. Such discourse markers of argumentation explicate logical reasoning for any argument and represent a sequential structure. But alongside these explicit devices a logical reasoning can be presented implicitly as well.

During the manifestation of argumentation these explicit and implicit relations construct certain information and cognitive structures in discourse. For example, it is obvious that metaphoric expressions do not explicitly support argumentation as strong as certain grammatical and lexical devices resulted in pragmatic perspectives, but the oppositions they construct give impetus to the receiver for relevant associations and eventually for strong cognitive operations.

There are two aspects of discourse analysis. One focuses on the structure of discourse while the other one explores discourse as the main factor to deal with the functions of morphological and syntactical units and devices. For example, articles, conjunctions, adverbs, word order can be explained by discourse strategies. But mainly the researches cover both aspects.

A number of factors might have an impact on the combination of social and communicative situations called discourse. But, of course, the main factors here are the type of discourse and the capacity of the sender for options. It is the problem of "choice" which was well studied in linguistics. A. Kuznetsov (Kuznetsov, 1991:30) writes: Any person who starts verbal communication is facing a choice in terms of function, style, pragmatics, social dimension as well as of territory.

We can identify at least three levels of language on which a sender makes choices: 1) the vocabulary choices that a sender makes; 2 ) the choice regarding the aspects of syntax; 3 ) the way these levels of language can operate in texts. The lexical and syntactic patterns as well as their function on the level of text are crucial in the structuring of information in discourse.

Conclusions. The theme is used in linguistics as part of an analysis of the communicative structure of sentence. It refers, not to the subject-matter of a sentence, but to the way sender identifies the relative importance of his/her subject matter, and is defined as the first major constituent of a clause. The elements which convey the new or important piece of information (the communicative nucleus) is the rheme. The elements that belong neither to theme nor rheme in a clause are transitional. In general, the thematic elements are communicatively less dynamic; therefore carry a smaller amount of communicative dynamism than the rhematic elements. The rheme in English is often signaled by the indefinite article, particles, time adverbs, determiners, the words like one or some. The theme is signaled by the definite article, personal and demonstrative pronouns a determiner. Another important signal of rheme in English is word order. As word order is relatively fixed, for example, in English, it can stylistically distinguish rheme, thus imposing pragmatic communicative dynamism. In fact, every language has various grammatical devices for certain communicative strategies. Thus, the theme and the rheme can be marked in a sentence by particles, definite and indefinite articles, personal and demonstrative pronouns, time adverbs and word order. The use of all these grammatical elements and phenomena is motivated by the pragmatic intentions of a sender. 


\section{REFERENCES}

1. Benveniste E. (1974) Probleme de linquistique generale, Vol. Paris: Gallimard.

2. Bertrand C. (1995) Medias. Introduction a la presse, la radio et la television: Paris.

3. Beugrande de R. (1980) Text, Discourse and Process toward a multidisciplinary Science of text. London: Longman.

4. Cap Piotr (2013) Proximization: The pragmatics of symbolic distance crossing. Amsterdam: John Benjamins.

5. ctives on Immigration Discourse. Basingstoke: Palgrave.

6. Derrida J. (1978) Writing and Difference, trans. Barbara Harlow, Chicago and London: University of Chicago Press.

7. Dijk Teun A. van (1977) Text and context. Explorations in in the semantics and pragmatics of discourse. London: Longman.

8. Dijk Teun A. van (1985) Introduction: Discourse analysis in (mass) communication research In: Discourse and communication: new approaches to the analysis of mass media discourse and communication / ed. by Teun A. van Dijk, Berlin: de Gruyter, p.1-13.

9. Dijk Teun A. van (1985) Semantic Discourse Analysis // Handbook of Discourse Analysis, London: Academic Press, p.103-136.

10. Dijk Teun A.van (2008) Discourse and context. A Sociocognitive Approach Cambridge: Cambridge University Press.

11. Enkvist N.E. (1989) From Text to Interpretability: A Contribution to the Discussion of Basic Terms in Text linguistics. Connexity and Coherence: Analysis of Text and Discourse Ed. By W. Heydrich. Berlin, New York: Mouton de Gruyter, p.369-382.

12. Evans V. (2013) Language and Time a Cognitive Linguistics Approach. Cambridge: Cambridge University Press.

13. Foley W.A. (1994) Information structure // The encyclopedia of language and linguistics. Oxford: Oxford University Press, V. 3.: 1678-1685.

14. Halliday M.A.K. (1968) Notes on transitivity and theme in English // Journal of Linguistics, London, v.3, p.37-81; 199-244.

15. Halliday M.A.K., Hasan R. (1976) Cohesion in English London: Longman.

16. Harris Z. (1952) Discourse Analysis, Language 28: 1-30.

17. Hart C. (2011) Critical Discourse Analysis and Cognitive Science: New Perspe.

18. Lyons J. (1981) Language, meaning and context. London: Fontana paperbacks.

19. Mammadov A. and Mammadov M. (2014) The role of figurative language in political discourse. M. Kuzniak, A. Libura, M. Szawerna (eds.) Studies in Language, Culture and Society. Vol. 3 Frankfurt am Main: Peter Lang Edition, p.113-127.

20. Saussure de L. (2007) Pragmatic issues in Discourse Analysis, CADAAD 1(1), p. 179-195.

21. Wodak R. (2009) The Discourse of Politics in Action. Politics as Usual. London: Palgrave Macmillan.

22. Гальперин И.Р. (1981) Текст как объект лингвистического исследования. Кибрик А.А. и др. (1997) Дискурс и возникновение функционализма. В книге: Фундаментальные направления современной американской лингвистики, Сб. сква: Наука. 